\title{
What is an Animal?
}

\author{
Review of Animal Encounters (2009) Edited by Tom Tyler \\ and Manuela Rossini, Leiden: Brill. 266pp \\ ISBN: 9789004168671. List price: $€$ 79.00/US\$ 117.00
}

\section{Stephen Pain}

Received: 13 July 2009 / Accepted: 20 July 2009 /

Published online: 15 October 2009

(C) Springer Science + Business Media B.V. 2009

What is an animal? One can define an animal scientifically, but for most of us, the way that we define an animal is through our interaction with it. The book under review now, is a compilation of essays, which explores and analyses the encounters humans have with animals, ranging from the quotidian to the most bizarre. The contributors are leading figures in animal studies, a field that has over recent years increased in prominence, this book will certainly help to promote it further.

In his own essay, "If Horses had Hands" (pp. 13-26) one of the editors. Tom Tyler, in the section titled "Potential Encounters" analyses the term "anthropomorphism", breaking it down into three forms, firstly in the literal sense of attribution (softcore attribution), secondly being overboard in attribution (hardcore attribution, as in walking talking animals), thirdly in attribution of human qualities to animals in the domain of scientific and philosophical literature (p. 14). After his analysis of the forms of anthropomorphism, Tyler argues that the central problem is perhaps spatial. We privilege the human, centre the relations on the human, rather than considering the possibility the terms of animality and humanity have distinct lineages.

Pamela Bunting in her chapter, "Magic is afoot: Hoof Marks, Paw Prints and the Problem of Writing Wildly" (pp. 27-44), in the main reviews two nature writers, Sid Marty and Andy Russell. Her thesis is interesting because she balks at the postmodernist penchant for contextualisation. Before humans constructed the environment socially, animals in their encounters and "languages" made sense of the world. Nature comes before social constructivism. The two non-fiction writers she analyses perform the function of intermediaries between the naturally inscripted world of hoof marks, paw prints, and that of the cultural world of the written text. In 
the second section of the book, titled "Mediate Encounters", the feminist and animal ethicist, Carol J. Adams writes in her essay, "Post Meateating" (pp. 47-72), about one element from her best-selling books on sexual politics of meat, namely the animal as the absent referent. Here she means that when we eat say a hamburger, the hidden or absent referent is the cow. We do not think of the referent as an existential entity at time of eating. Nor do we make the connection between the bacon we put in our mouths with the violence of the slaughterhouse. Adams addresses this and provides examples of artists who have alerted us to this truth, including the film director David Lynch's "Eat My Fear" (2000) (pp. 48-49). She also discusses the paradigmatic shift from modernist attitudes to postmodernist attitudes, usefully tabulating the binaries, before investigating each one in detail (p. 52). For example, the shift from animal rights (modern) to animal rites (postmodern).

Randy Malamud's chapter turns on the joke, "Americans do Weird Things with Animals, or, Why did the Chicken cross the Road?" (pp. 73-96). that he sees as a gross case of speciesism and a cultural misreading of birds. Humans are in the business of "disempowering" the threat of nature and we do this in our cultural productions (p. 73). What we do in culture, Malamud states, serves as model for how we treat animals in nature. His essay is an interrogation of silly high-humanism that fails to observe animals for what they are. Several of his examples are taken from popular culture like the kitsch tiger performers, Siegfried \& Roy, the Disney animation Finding Nemo (2003) (pp. 87-92). In the case of the tiger show, Roy had wrongfully misread the relations between him and the tiger, insisting in a dreadfully anthropomorphic way that the mauling he received was actually the consequence of the animal trying to protect him. Similarly in the example of the Disney movie, children went out to buy real Clownfish because they thought it would be cool to have something like Nemo, however they misunderstood the message which was that Nemo wanted to be free of the aquarium!

A third section in the book titled "Experimental Encounters" delves into the encounters of scientists. First up is Robyn Smith's account of the fate of laboratory animals in the history of vitamins, "Affect, Friendship and the "As Yet Unknown": Rat Feeding Experiments in Early Vitamin Research" (pp. 100-114). She uses the metaphor of the maze in cognition testing as a tool of analogy for analysis of the research in the 1930's. The scientists do not fare very well. She cogently argues that scientists got lost in the repetition of experimentation. At some stage, she suggests, the experiment more or less took a life of its own, the scientist sat back and the system organised the pointless slaughter of animals for the sake of the experiment, and not science. Any interaction between the scientist and animal could not be misconstrued as affectionate or bonding, stroking had an end, that was the end of the test subject.

The following essay by Donna Hathaway begins with a glance at a young-adult novel, A Girl Named Disaster (1996) by Nancy Farmer that includes a description of an old African man who cared for guinea pigs used in sleeping sickness research. Faced with what he saw as cruelty, he felt the urge to put himself in the same situation by thrusting his arm into a tstetse cage and letting the blood hungry flies dine on him. This selfless act is a statement of copresence, i.e. recognising that animals are also present. Drawing on an earlier essay of hers about a mouse used in cancer research, Derrida and the novels of the South African writer J.M. Coetze, and 
a short autobiographical text by Hélène Cixous, among others, Haraway through the tangles of intertextualisation and perspectives, constructs an ethical position, more of a hope that scientists might seek to embrace the hereness, the presence of the experimentees - to respond, share, and seek Grace rather than Disgrace after the sacrifice.

The fourth section titled corporeal encounters begins with an essay by Laurie Shannon, "Renaissance Anatomies" (pp. 136-157) on the renaissance conception of the human/animal "big gap", one underpinned by Descartes cogito ergo sum. As an intellectual act of resistance, Shannon develops a case for relatedness based on Aristotelian philosophy rather than the empirical division. Indeed, she goes further and argues for a "zootopian constitution". (p. 140) By close reading of the canonical classical and Renaissance texts on anatomy, Shannon deconstructs the Cartesian monument to humaness that was based on scientific reasoning, since his statement, has no actual correlate - there is no I, just like when Thomas Browne studied the crania of both men and beasts and found them to be the same-how could one accept the subjective I and the human soul as indicators of difference, if the anatomy of their putative locations were no different in animals.

Jonathan Burt follows, in an essay titled "Invisible Histories: Primate Bodies and the Rise of Posthumanism in the Twentieth Century" (pp. 159-170) that briefly describes posthumanism, then explores how animal history such as the history of primates in primatological research may be utilised to analyse the term posthuman. The trajectory of animal science had touched upon and "manufactured" the hybrid of animal and machine, as formulated in Donna Haraway's seminal writings of cyborgs. We can see even in the primate research of Solly Zuckerman in the 1920's to 1940's, the dissolution of the Cartesian divide, because the nonhumans were treated and imagined to be humans in the tests-it was important for all that the results were to be taken as if, for example, a human being was actually involved in a bomb blast and not a rhesus monkey being repeatedly struck on the head. This fiction, is equivalent to that in the classical human anatomy text books after Galen which were based on monkeys and not humans. Susan Squier's essay on a women and chickens, "Fellow-Feeling" (pp. 173-196) heads the next theme, "Domestic Encounters". Focussing firstly on the life of a nineteenth century woman farmer, Miss Nancy Luce who became famous for her methods of chicken rearing, Squier asserts a novel thesis for a farming economy based on the Eighteenth century Adam Smith's notion of "fellow feeling", an equivalent to some extent to the above concept of shared responsibility and copresence in Donna Haraway's essay. Nancy Luce the farmer cared for and deeply loved her chickens, as evinced by her poetic outpourings which though not the best of poetry encapsulate nicely her sentiments.

Something similar is found in the autobiographical work of Betty MacDonald who ran with her husband a chicken farm in the 1940's. By then chicken farming, it hitherto had been mostly women who farmed, and the scale had shifted from single owned farms to intensive large scale production, began to alienate the farmer from the chicken. The subject of a photographic essay, Linda Lord working in the slaughter end of factory farming, terminates the analysis (pp. 185-189). However even in this instance, in the "killing tunnel", there is evidence of the Smithian fellow-feeling. Squier argues, that at each stage, optimistically it should 
be a small concern, there should be a sense of fellow-feeling and communality in keeping with the moral sentiments of Adam Smith and the wishes of feminists through history.

Steve Baker takes a look at another eccentric, an artist Lucy Kimball who has focused on the lab rat in her art, as a point of departure in his essay, "“Tangible and Real and Vivid and Meaningful": Lucy Kimbell's Not-Knowing about Rats" (pp. 197-218). Her art parodies and parallels the lot of the rat in the laboratory. Indeed she uses the Tolman kind of experiments for an aesthetic adventure, one that engages the audience is a revaluation of their interaction with rats. The epistemological twist, the "not-knowing" links up with Robyn Smith's thesis of the drive of science towards the "as yet not known". In addition Kimbell encourages a scientific reading of her art, knowing it to be "bad science", a tactic that like her "cute poetry" deliberately decentres the normative critique. Baker sees this extended performative art, as a site of ambiguity, because the rat is undeniably being used, though here it is in the name of art, and the ethics of which might fall foul of Jonathan Burt's idea of "weird" or "silliness".

The most controversial section of the book, the final one, "Libidinal Encounters" includes two essays on human/animal sexual encounters, the type once labelled pejoratively zoophilia or bestiality. The first essay by Monika Bakke, "The Predicament of Zoopleasures: Human-Nonhuman Libidinal Relations" (pp. 221-242) bravely investigates the current scene of what is known as zoosexuality. The "zoos" are people who view their relationship with animals to be predicated on partnership rather than the master/slave dialectic - their loving relationship is supported by legislation in several European countries where sexual acts with animals are legal as long as they are consensual. This quite bizarre sexual orientation pushes the borders of artistic licence further, as some artists whether as an act of provocation or belief, use zoophilia as a theme, though here as in many areas the Greeks and Romans in mythology and literature were thousands of years ahead of the game! As elsewhere in the book, there are illustrations, here the picture of a woman holding a horse's penis and a man lying naked next to a dog, two works of art, can be shocking for those more prudish. But it is after all a taboo subject, and like all forms of sexuality more widespread than some people would want to admit. Bakke sees the appropriation of the zoosexual by the artists Andres Serrano and Oleg Kulik as a statement of posthumanist intent, in other words an acceptance of the premise that corporeality is no longer bounded by the human body, like Frank Lloyd Wright's conception of architectural space, the body projects into the zoosphere.

The last essay by one of the book's editors, Manuela Rossini, "Coming together: Symbiogenesis and Metamorphosis in Paul di Filippo's A Mouthful of Tongues" (pp. 243-258) concentrates on a novel by Paul di Filippo a SF book (2003) that has a heroine who dreams of zoosexual encounters, is raped by her husband, then in the laboratory transforms herself into an "animal" that can have sex with nearly everything in the Rain Forest, including the dream jaguars. Using the plot of the novel, Rossini constructs an argument for meta- or dream position in relation to animals, where the relation is not abused as in the rape, but celebrated, like the "oral intercourse" Donna Haraway has with her pet German shepherd (pp. 244-245). 
The object of the collection of essays by leading figures in animal studies has been to test the limits of the discourse between animals and humans, to deliberately shock us into seeing behind the Disneyfied image of animals and our all too ready acceptance of a weighted anthropomorphism. Several of the essays have semiotic themes explicitly or implicitly, all treat representation and relations, all of which in sum is fascinating, stimulating, and above all informative; about encounters we ourselves have with animals, including those we would not like to talk about. 